\title{
MODEL SISTEM INFORMASI SURAT PERINTAH TUGAS DAN SURAT PERINTAH PERJALANAN DINAS BERBASIS WEB (STUDI KASUS: AMIK INDONESIA)
}

\author{
Munawir $^{1 *}$, Rahmi Hajriyanti ${ }^{2}$ \\ 1,2 Program Studi Manajemen Informatika, Fakultas Ilmu Komputer, \\ AMIK Indonesia, Jl. T Nyak Arief Sp Mesra No. 400, Kota Banda Aceh, Indonesia \\ Email: munawir@amikindonesia.ac.id ${ }^{1}$,rahmihajriyanti@amikindonesia.ac.id ${ }^{2}$
}

\begin{abstract}
Abstrak
Tujuan penelitian yaitu membangun sebuah model program berbasis website untuk pembuatan sistem informasi surat perintah tugas dan surat perintah perjalanan dinas berbasis website. Untuk proses pengembangan aplikasi menggunakan model waterfall, dan diagram alir data digunakan untuk diagram alir data logika untuk menggambarkan sistem yang akan diusulkan. Kesimpulan dari hasil penelitian ini adalah; 1) Sistem informasi surat perintah perjalanan dinas pada Kampus AMIK Indonesia dikembangkan untuk mempermudah pengolahan informasi SPPD bagi staff sehingga menjadi lebih efektif dan efesien, dan 2) Sistem informasi surat perintah perjalanan dinas pada Kampus AMIK Indonesia dikembangkan berbasiskan web dengan menggunakan PHP dan Mysql sebagai database sehingga menghasilkan form input SPPD, form input data pegawai, form provinsi, kabupaten dan laporan SPPD.
\end{abstract}

Kata Kunci: Model; Sistem Informasi; Surat Perintah Tugas dan Surat Perintah Perjalanan Dinas; Berbasis Web.

\begin{abstract}
The purpose of the research is to build a website-based program model for the creation of a websitebased information system for assignment warrants and official travel warrants. For the application development process using the waterfall model, and data flow diagrams are used for logical data flow diagrams to describe the system to be proposed. The conclusions from the results of this study are; 1 ) The official travel order information system at the AMIK Indonesia Campus was developed to facilitate the processing of SPPD information for staff so that it becomes more effective and efficient, and 2) The official travel order information system at the AMIK Indonesia Campus was developed web-based using PHP and Mysql as databases thus producing SPPD input forms, employee data input forms, provincial, district and SPPD reports.
\end{abstract}

Keyword: Model; Information Systems; Assignment Warrant and Official Travel Warrant; Web-based. 


\section{Pendahuluan}

Dalam dunia yang canggih seperti sekarang ini, manusia dituntut untuk menguasai berbagai teknologi yang salah satunya adalah menguasai computer [1,2]. Semua itu digunakan agar manusia bisa bekerja dengan cepat dan optímal. Sejalan dengan majunya dunia teknologi yang mampu mendorong semua instansi, baik pemerintah maupun swasta yang telah mengikuti teknologi dalam menyelesaikan setiap program kerja yang ada [3], oleh karena itu Akademi Manajemen Informatika dan Komputer (AMIK) Indonesia telah menggunakan komputer untuk menyelesaikan berbagai program kerja di setiap kegiatan dalam pengolahan data [4,5]. Surat merupakan suatu sarana untuk menyampaikan informasí secara tertulis kepada pihak lain, baik atas nama dirinya sendiri, atas nama orang lain maupun jabatannya di dalam suatu organisasi. Informasi iní dapat berupa pemberitahuan, pertanyaan, permintaan atau buah pikiran yang ingin disampaikan kepada pihak lain, baik perseorangan maupun organisasi. Akademi Manajemen Informatika dan Komputer (AMIK) Indonesia adalah salah satu lembaga yang masih mengunakan Microsoft Word dan Microsoft Excel untuk pengolahan data dan penyimpanan data Surat Perintah Tugas dan Surat Perintah Perjalanan Dinas. Surat Perintah Perjalanan Dinas (SPPD), yaitu surat pengantar yang dibuat ketika pegawainya akan melakukan perjalanan dinas ke kota tertentu Dalam pembuatannya masih menggunakan aplikasi Microsoft Word dimana harus dilakukan pengeditan setiap kali akan melakukan perjalanan dinas. Selain itu pembuat SPPD harus mencari data setiap pegawai yang akan melakukan perjalanan dinas pada Microsoft Excel sehingga banyak terjadi kesalahan-kesalahan pengetikan dalam menginputkan data. Hal ini menyebabkan pembuatan SPPD dilakukan berulangulang dan banyaknya kertas yang terbuang, selain itu waktu yang dibutuhkan menjadi lebih lama.

Berdasarkan hal tersebut, maka peneliti tertarik untuk melakukan penelitian untuk membangun sebuah model program berbasis website untuk pembuatan Sistem Informasi Surat Perintah Tugas dan Surat Perintah Perjalanan Dinas, karena program berbasis Website adalah merupakan situs informasi yang dapat diakses secara cepat. Website ini didasari dari adanya perkembangan teknologi informasi dan komunikasi. Melalui perkembangan teknologi informasi, tercipta suatu jaringan antar komputer yang saling berkaitan. Jaringan yang dikenal dengan istilah internet secara terus-menerus menjadi pesan-pesan elektronik, termasuk e-mail, transmisi file, dan komunikasi dua arah antar individu atau komputer.

\section{Metode Penelitian}

Dalam pembuatan model ini peneliti menyusun diagram alir data yang digunakan adalah diagram alir data logika untuk menggambarkan sistem yang akan diusulkan [6,7]. Penekanannya pada logika dari kebutuhan-kebutuhan sistem $[8,9,10]$, yaitu proses-proses apa secara logika yang dibutuhkan oleh sistem. Komponennya adalah :

a) Kesatuan Luar (External entity).

Kesatuan luar merupakan kesatuan (entity) di lingkungan luar sistem yang dapat berupa orang, organisasi atau sistem lainnya yang berada di lingkungan luarnya yang akan memberikan input atau menerima output dari sistem [11].

b) Arus Data (Data flow)

Arus data menunjukkan arus dari data yang dapat berupa masukan untuk sistem atau hasil dari proses sistem. Arus data ini mengalir diantara proses, simpanan data dan kesatuan luar [12].

c) Proses (Process)

Proses adalah kegiatan atau kerja yang dilakukan oleh orang, mesin atau komputer dari hasil suatu arus data yang masuk ke dalam proses untuk dihasilkan arus data yang akan keluar dari proses [13].

d) Simpanan Data (Data Store)

Simpanan data merupakan simpanan dari data yang berupa suatu file atau database di sistem computer [14]. 
Untuk proses pengembangan aplikasi menggunakan model waterfall. Untuk database disusun dalam 5 kelompok sesuai dengan tabel berikut:

Tabel 1. Database Users

\begin{tabular}{cllll}
\hline No & \multicolumn{1}{c}{ Nama Field } & Type Data & Field Size & Keterangan \\
\hline 1. & Id_User & Int & 11 & Primary Key \\
2. & Nama & Varchar & 40 & \\
3. & Username & Varchar & 20 & \\
4. & Password & Varchar & 8 & \\
\hline
\end{tabular}

Tabel 2. Database Surat Tugas

\begin{tabular}{|c|c|c|c|c|}
\hline No & Nama Field & Type Data & Field Size & Keterangan \\
\hline 1. & Id_surat_tugas & Int & 11 & Primary Key \\
\hline 2. & No_surat & Varchar & 20 & \\
\hline 3. & Id_pegawai & Int & 12 & \\
\hline 4. & Tujuan & Varchar & 100 & \\
\hline 5. & Untuk & Vachar & 100 & \\
\hline 6. & Dari_Tanggal & Vachar & 10 & \\
\hline 7. & Transportasi & Vachar & 50 & \\
\hline 8. & Tanggal_Surat & Time Stamp & - & \\
\hline 9. & Memo_surat & Vachar & 100 & \\
\hline 10. & Tanggal_memo & Time Stamp & - & \\
\hline
\end{tabular}

Tabel 3. Database Surat Tugas

\begin{tabular}{cllll}
\hline No & \multicolumn{1}{c}{ Nama Field } & Type Data & Field Size & Keterangan \\
\hline 1. & Id_surat_dinas & Int & 11 & Primary Key \\
2. & Devisi & Varchar & 50 & \\
3. & Lembar & Varchar & 50 & \\
4. & Kode_no & Varchar & 10 & \\
5. & No_surat & Vachar & 20 & \\
6. & Pejabat_berwenang & Vachar & 100 & \\
7. & Id_pegawai & Int & 12 & \\
8. & Tanggal_surat & Time Stamp & - & \\
\hline
\end{tabular}

Tabel 4. Database Jabatan

\begin{tabular}{cllll}
\hline No & \multicolumn{1}{c}{ Nama Field } & Type Data & Field Size & Keterangan \\
\hline 1. & Id_Jabatan & Int & 11 & Primary Key \\
2. & Kode_Jabatan & Varchar & 5 & \\
3. & Nama_Jabatan & Varchar & 50 & \\
\hline
\end{tabular}

Tabel 5. Database Pegawai

\begin{tabular}{|c|c|c|c|c|}
\hline No & Nama Field & Type Data & Field Size & Keterangan \\
\hline 1. & Id_Pegawai & Int & 11 & Primary Key \\
\hline 2. & NIP & Varchar & 12 & \\
\hline 3. & Nama & Varchar & 50 & \\
\hline 4. & Golongan & Varchar & 10 & \\
\hline 5. & Pangkat & Varchar & 10 & \\
\hline 6. & Id_Jabatan & Int & 10 & \\
\hline
\end{tabular}




\section{Hasil dan Pembahasan}

Model Sistem Informasi surat perintah perjalanan dinas pada AMIK Indonesia Berbasis Web ini akan dijelaskan dengan pembahasan secara umumnya yaitu mulai halaman form input dan hasil laporan dari sistem.

Halaman Login

Halaman login pertama kali sebelum user masuk ke dalam sistem adalah halaman login, halaman login dapat dilihat pada gambar 2, halaman ini dirancang supaya user yang menggunakan sistem adalah user yang berhak dalam menginput data. Halaman dapat diakses jika seorang user telah terdaftar sebagai operator atau administrator AMIK Indonesia. Sistem pendaftaran user dilakukan oleh admin, dengan mengakses form data user.

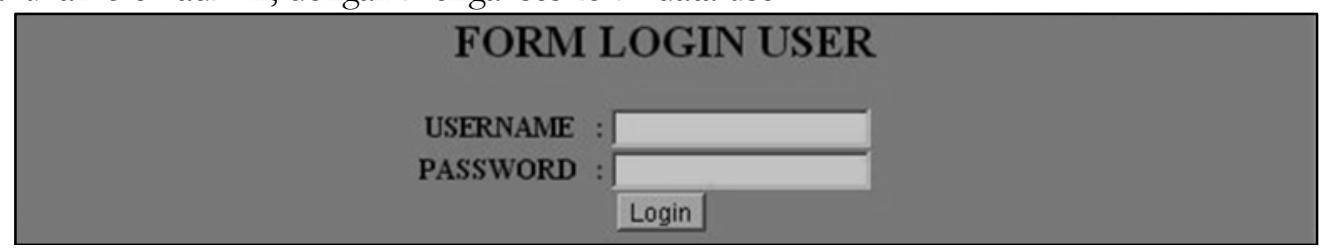

Gambar 2. Form Login

\section{Form Input Data SPPD}

Pada sistem ini terdapat form input data SPPD yang berfungsi tempat menginput data surat perintah perjalanan dinas atau SPPD. Form ini hanya dapat diakses oleh user dengan level operator dan administrator. Data yang diinput adalah No.SPPD, id_pejabat, nama pegawai, lama perjalanan, berangkat dari, tujuan ke, anggaran, tanggal perjalanan, maksud, beban dan jenis transportasi. Untuk menyimpan user mengklik tombol button Simpan.

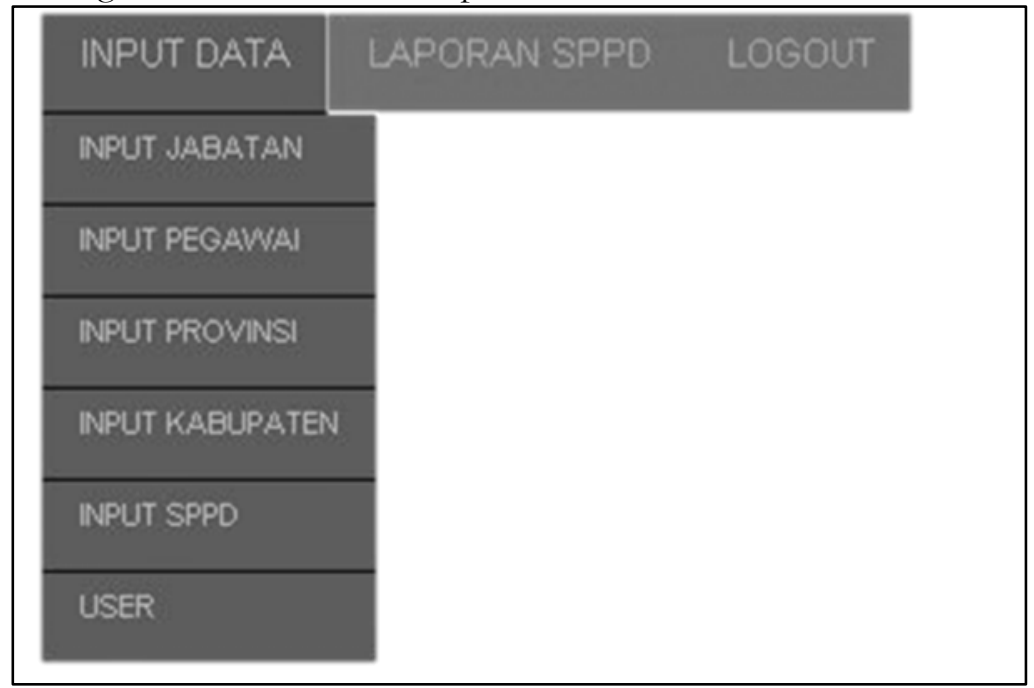

Gambar 3. Menu Input Data SPPD

Form Input Data Jabatan

Pada sistem ini terdapat form input data Jabatan yang berfungsi tempat menginput data jabatan pegawai. Form ini hanya dapat diakses oleh user dengan level operator dan administrator. Data yang diinput adalah nama jabatan saja. Untuk menyimpan user mengklik tombol button Simpan. Hasil yang disimpan akan terekam pada Database. 


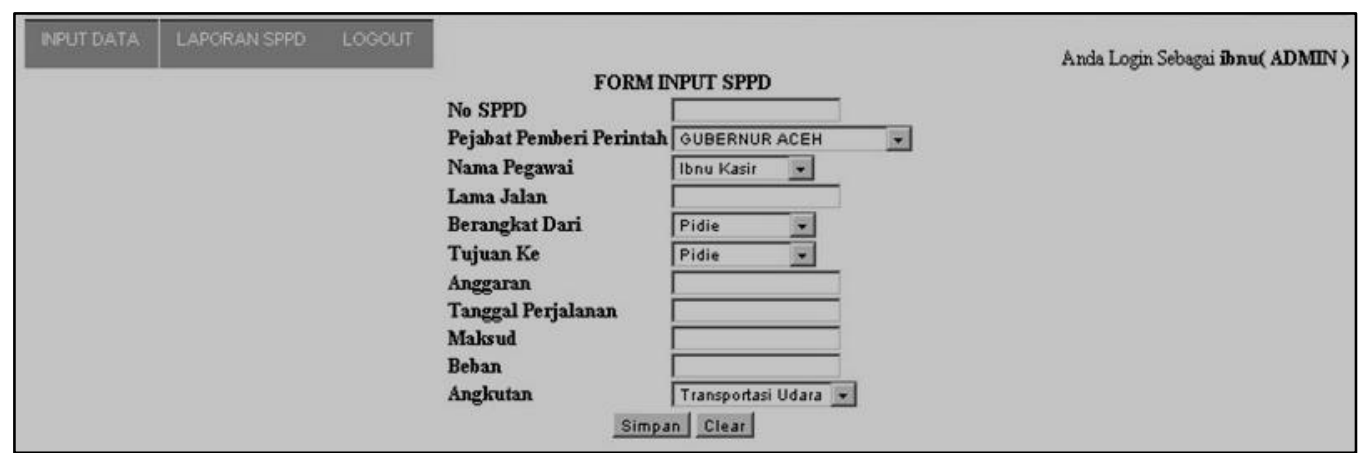

Gambar 4. Form Input Jabatan

\section{Kesimpulan dan Saran}

Penelitian yang telah ini adalah sebuah model sistem informasi surat perintah perjalanan dinas pada Kampus AMIK Indonesia Berbasis Web yang diharapkan dapat berguna untuk mempermudah di dalam pemrosesan data agar bisa lebih mengefisienkan waktu.

Adapun kesimpulan dari penelitian ini adalah sebagai berikut:

a) Sistem informasi surat perintah perjalanan dinas pada Kampus AMIK Indonesia dikembangkan untuk mempermudah pengolahan informasi SPPD bagi staff sehingga menjadi lebih efektif dan efesien.

b) Sistem informasi surat perintah perjalanan dinas pada Kampus AMIK Indonesia dikembangkan berbasiskan web dengan menggunakan PHP dan Mysql sebagai database sehingga menghasilkan form input SPPD, form input data pegawai, form provinsi, kabupaten dan laporan SPPD.

Rancangan sistem informasi ini masih banyak kekurangan baik bagi peneliti maupun pihak kampus AMIK Indonesia. Oleh karenanya, maka peneliti memberikan peran-peran untuk perbaikan kedepannya yaitu:

a) Diharapkan partisipasi dari pihak kampus AMIK Indonesia untuk memelihara dan memperbaharui sistem informasi website ini.

b) Ketepatan dalam proses pengisian data perlu diperhatikan agar tidak terjadi kesalahan dalam proses pengisian data karena dapat berakibat fatal dalam proses pengolahan Informasi yang akan disampaikan.

\section{Daftar Pustaka}

[1] König, J., Jäger-Biela, D.J. and Glutsch, N., 2020. Adapting to online teaching during COVID-19 school closure: teacher education and teacher competence effects among early career teachers in Germany. European Journal of Teacher Education, 43(4), pp.608-622.

[2] Nelson, R.R., 2019. On technological capabilities and their acquisition. In Science and Technology (pp. 71-80). Routledge.

[3] Simarmata, J., Chaerul, M., Mukti, R.C., Purba, D.W., Tamrin, A.F., Jamaludin, J., Suhelayanti, S., Watrianthos, R., Sahabuddin, A.A. and Meganingratna, A., 2020. Teknologi Informasi: Aplikasi dan Penerapannya. Yayasan Kita Menulis. 
[4] Mukhtar, M. and Munawir, M., 2018. Aplikasi Decision Support System (DSS) dengan Metode Fuzzy Multiple Attribute Decission Making (FMADM) Studi Kasus: AMIK Indonesia Dan STMIK Indonesia. Jurnal JTIK Jurnal Teknologi Informasi dan Komunikasi), 2(1), pp.57-70.

[5] Akbar, R. and Mukhtar, M., 2019. E-Tracer Study Based on Expert Systems (A Case Study at AMIK Indonesia). EPH-International Journal of Science And Engineering, 5(5), pp.12-17.

[6] Febriani, O.M. and Putra, A.S., 2013. Sistem Informasi Monitoring Inventori Barang Pada Balai Riset Standardisasi Industri Bandar Lampung. Jurnal Informatika, 13(1), pp.90-98.

[7] Gao, M., Yang, X., Pu, J., Horowitz, M. and Kozyrakis, C., 2019, April. Tangram: Optimized coarse-grained dataflow for scalable nn accelerators. In Proceedings of the TwentyFourth International Conference on Architectural Support for Programming Languages and Operating Systems (pp. 807-820).

[8] Khorunzhak, N., Brukhanskyi, R. and Ivanyshyn, V., 2019. Logic-statistical information models in control function of accounting. Independent Journal of Management \& Production, 10(7), pp.846-871.

[9] Yu, B. and Silva, C.T., 2019. FlowSense: A natural language interface for visual data exploration within a dataflow system. IEEE transactions on visualization and computer graphics, 26(1), pp.1-11.

[10] Chen, Y., Xie, Y., Song, L., Chen, F. and Tang, T., 2020. A survey of accelerator architectures for deep neural networks. Engineering, 6(3), pp.264-274.

[11] Svobodová, L. and Černá, M., 2018, September. Project management model with designed data flow diagram: The case of ICT hybrid learning of elderly people in the Czech Republic. In International Conference on Computational Collective Intelligence (pp. 399-408). Springer, Cham.

[12] Yu, B. and Silva, C.T., 2019. FlowSense: A natural language interface for visual data exploration within a dataflow system. IEEE transactions on visualization and computer graphics, 26(1), pp.1-11.

[13] Wan, W., Kubendran, R., Eryilmaz, S.B., Zhang, W., Liao, Y., Wu, D., Deiss, S., Gao, B., Raina, P., Joshi, S. and Wu, H., 2020, February. 33.1 a 74 tmacs/w cmos-rram neurosynaptic core with dynamically reconfigurable dataflow and in-situ transposable weights for probabilistic graphical models. In 2020 IEEE International Solid-State Circuits Conference-(ISSCC) (pp. 498-500). IEEE.

[14] Sion, L., Dewitte, P., Van Landuyt, D., Wuyts, K., Emanuilov, I., Valcke, P. and Joosen, W., 2019, March. An architectural view for data protection by design. In 2019 IEEE International Conference on Software Architecture (ICSA) (pp. 11-20). IEEE. 